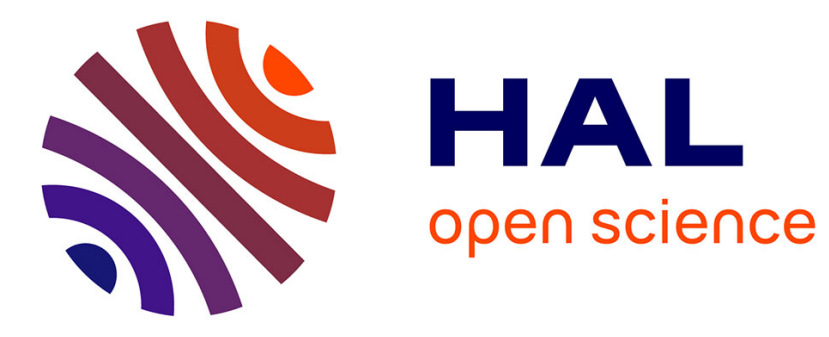

\title{
Clarithromycin modulates immune responses in experimental peritonitis
}

Stefanos Atmatzidis, Ioannis Koutelidakis, Grigorios Chatzimavroudis, Konstantinos Louis, Aikaterini Pistiki, Konstantinos Roditis, Konstantinos Atmatzidis, Evangelos J. Giamarellos-Bourboulis

\section{To cite this version:}

Stefanos Atmatzidis, Ioannis Koutelidakis, Grigorios Chatzimavroudis, Konstantinos Louis, Aikaterini Pistiki, et al.. Clarithromycin modulates immune responses in experimental peritonitis. International Journal of Antimicrobial Agents, 2011, 37 (4), pp.347. 10.1016/j.ijantimicag.2010.11.037 . hal00679596

\section{HAL Id: hal-00679596 https://hal.science/hal-00679596}

Submitted on 16 Mar 2012

HAL is a multi-disciplinary open access archive for the deposit and dissemination of scientific research documents, whether they are published or not. The documents may come from teaching and research institutions in France or abroad, or from public or private research centers.
L'archive ouverte pluridisciplinaire HAL, est destinée au dépôt et à la diffusion de documents scientifiques de niveau recherche, publiés ou non, émanant des établissements d'enseignement et de recherche français ou étrangers, des laboratoires publics ou privés. 


\section{Accepted Manuscript}

Title: Clarithromycin modulates immune responses in experimental peritonitis

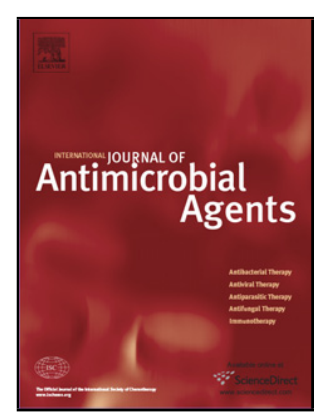

Authors: Stefanos Atmatzidis, Ioannis Koutelidakis, Grigorios

Chatzimavroudis, Konstantinos Louis, Aikaterini Pistiki,

Konstantinos Roditis, Konstantinos Atmatzidis, Evangelos J.

Giamarellos-Bourboulis

PII:

DOI:

S0924-8579(11)00038-0

Reference: doi:10.1016/j.ijantimicag.2010.11.037

ANTAGE 3530

To appear in: International Journal of Antimicrobial Agents

Received date: $\quad 16-7-2010$

Revised date: $\quad 18-11-2010$

Accepted date: $\quad 18-11-2010$

Please cite this article as: Atmatzidis S, Koutelidakis I, Chatzimavroudis G, Louis K, Pistiki A, Roditis K, Atmatzidis K, Giamarellos-Bourboulis EJ, Clarithromycin modulates immune responses in experimental peritonitis, International Journal of Antimicrobial Agents (2010), doi:10.1016/j.ijantimicag.2010.11.037

This is a PDF file of an unedited manuscript that has been accepted for publication. As a service to our customers we are providing this early version of the manuscript. The manuscript will undergo copyediting, typesetting, and review of the resulting proof before it is published in its final form. Please note that during the production process errors may be discovered which could affect the content, and all legal disclaimers that apply to the journal pertain. 


\section{Clarithromycin modulates immune responses in experimental peritonitis}

Stefanos Atmatzidis ${ }^{a}$, loannis Koutelidakis ${ }^{a}$, Grigorios Chatzimavroudis ${ }^{a}$, Konstantinos Louis ${ }^{\mathrm{b}}$, Aikaterini Pistiki ${ }^{\mathrm{b}}$, Konstantinos Roditis ${ }^{\mathrm{b}}$, Konstantinos Atmatzidis $^{a}$, Evangelos J. Giamarellos-Bourboulis ${ }^{b, *}$

a 2nd Department of Surgery, University of Thessaloniki, Medical School, Greece

b 4th Department of Internal Medicine, University of Athens, Medical School, Greece

ARTICLE INFO

Article history:

Received 16 July 2010

Accepted 18 November 2010

Keywords:

Clarithromycin

Apoptosis

Peritonitis

$\mathrm{TNF} \alpha$

* Corresponding author. Present address: 4th Department of Internal Medicine, ATTIKON University Hospital, 12462 Athens, Greece. Tel.: +30 2105831994.

E-mail address: giamarel@ath.forthnet.gr (E.J. Giamarellos-Bourboulis). 


\section{ABSTRACT}

Based on clinical data revealing a promising immunomodulatory effect of clarithromycin in sepsis due to ventilator-associated pneumonia, the efficacy of clarithromycin in experimental peritonitis and sepsis was assessed with particular emphasis on immune function. Cecal puncture and ligation was performed in rabbits assigned to the following groups: Group A, controls $(n=12)$; Group B, intravenous clarithromycin treatment $(n=15)$; Group C, piperacillin/tazobactam (TZP) treatment $(n=10)$; and Group D, clarithromycin + TZP combination treatment $(n=12)$. Blood was sampled at serial time intervals and peripheral blood mononuclear cells (PBMCs) were isolated. Apoptosis of lymphocytes and monocytes was measured by flow cytometric analysis. PBMCs were stimulated with lipopolysaccharide (LPS) and Pam3Cys for the release of tumour necrosis factor-alpha (TNF $\alpha)$. Tissue bacterial growth was quantitatively measured after death or sacrifice. Survival in Group D after 10 days was prolonged compared with the other groups. Early apoptosis of lymphocytes in Group B was lower compared with Group D at $2 \mathrm{~h}$ and compared with Group C at $4 \mathrm{~h}$. Early apoptosis of monocytes in Group B was lower compared with Group $\mathrm{C}$ at $24 \mathrm{~h}$. Following stimulation of PBMCs with LPS, release of TNF $\alpha$ was decreased in Group B compared with Groups A and D at $2 \mathrm{~h}$. Bacterial growth in tissues of Groups C and D was decreased compared with Group A. It is concluded that clarithromycin modulates the function of the immune response in experimental peritonitis by decreasing the rate of early apoptosis of lymphocytes and monocytes and by decreasing the ex vivo release of TNF $\alpha$ by blood monocytes. 


\section{Introduction}

Severe sepsis and septic shock are among the leading causes of death. It is estimated that almost 3 million cases occur annually in Northern America and Europe, $35-50 \%$ of whom die [1]. This enormous death rate has led physicians to realise that single antibiotics cannot alter mortality and that other factors apart from the microbes themselves impact on patient outcome. One of the most important factors appears to be the pathogen-host interaction. The host's septic reaction is initiated when well conserved microbial structures known as pathogen-associated molecular patterns (PAMPs) bind to receptors embedded either on the cell membrane or inside the cell cytoplasm of cells of the innate immune system, namely blood monocytes and tissue macrophages. These receptors are known as pattern recognition receptors (PRRs). Toll-like receptors (TLRs) are among the best studied PRRs. Eleven TLRs have been recognised. Monomers of the cell wall peptidoglycan of Gram-positive cocci bind to TLR2, and lipopolysaccharide (LPS) of the outer membrane of Gram-negative bacteria binds to TLR4. The interaction of TLRs with PAMPs leads to activation of a series of intracellular pathways ending with the production of pro-inflammatory cytokines such as tumour necrosis factor-alpha (TNF $\alpha$ ), interleukin (IL)-1 $\beta$, IL-6 and IL-8. These pro-inflammatory mediators orchestrate the septic reaction of the host leading to severe sepsis and multiple organ dysfunction syndrome (MODS) [2].

Increase in current knowledge on the pathogenesis of sepsis created the concept of developing therapeutic agents that can modulate the microbial-host interaction. Several agents have been tested in clinical trials. Antibodies targeting LPS and TNF $\alpha$, soluble receptors targeting TNF $\alpha$ and IL-1 $\beta$, recombinant human activated 
protein $\mathrm{C}$, continuous infusion of insulin, and hydrocortisone replacement have all been administered with contradictory results [3]. One recently described approach is intravenous (i.v.) administration of clarithromycin, which was initially tested in a model of acute pyelonephritis and sepsis in rabbits. This model represents a monomicrobial type of experimental sepsis. Gram-negative bacteria, either susceptible or multidrug-resistant to antimicrobials, were applied as challenge. Intravenous treatment with clarithromycin was started either in parallel with bacterial challenge or when signs of sepsis appeared. Co-administration of clarithromycin and antimicrobials prolonged survival and attenuated the systemic inflammatory response [4-8]. However, the effect of clarithromycin on the function of monocytes was not studied.

Based on the above experimental results, a double-blind randomised clinical trial was designed of patients with sepsis developed in the field of ventilator-associated pneumonia (VAP). Two hundred patients were allocated to i.v. placebo or clarithromycin for 3 consecutive days through a central catheter. Antimicrobial therapy was administered according to standard guidelines. Results revealed that clarithromycin treatment was associated with a significant reduction in the risk of death by septic shock and MODS as well as significant earlier resolution of VAP. However, it should be underscored that VAP is a monomicrobial infection [9].

Acute intra-abdominal infection (IAI) is recognised as the third most common cause of sepsis [10]. It is polymicrobial in origin and generates a high bacterial load that disseminates very quickly via the rapidly absorbing peritoneum into the entire body. Polymicrobial infections create more complex microbial-host interactions compared 
with monomicrobial infections, making the efficacy of immunomodulatory treatment questionable [11].

In the present study, clarithromycin was administered intravenously in an animal model of intra-abdominal sepsis with high bacterial load. The immune function of the host was closely monitored in order to determine the effect of clarithromycin.

\section{Animals and methods}

\subsection{Animals}

A total of 59 male White New Zealand rabbits with a mean \pm standard deviation (S.D.) weight of $3.19 \pm 0.30 \mathrm{~kg}$ were studied. The study received a permit from the Veterinary Directorate of the Prefecture of Thessaloniki according to Greek legislation in conformance with the 160/1991 Council Directive of the European Union. Animals were housed in single metal cages and had access to tap water and standard balanced rabbit chow ad libitum. Room temperature ranged between $18^{\circ} \mathrm{C}$ and $22{ }^{\circ} \mathrm{C}$, relative humidity between $55 \%$ and $65 \%$ and the light/dark cycle was 06:00h/18:00h.

\subsection{Model of peritonitis}

Animals were initially sedated by intramuscular (i.m.) injection of $25 \mathrm{mg} / \mathrm{kg}$ ketamine and $5 \mathrm{mg} / \mathrm{kg}$ xylazine, and anaesthesia was maintained by i.m. administration of 15 $\mathrm{mg} / \mathrm{kg}$ xylazine at 30-min intervals. The peritoneal cavity was entered through an upper midline abdominal incision and the intestines were displaced to the left. The 
caecum was recognised and was ligated with a 3.0 suture. Three punctures were performed just above the suture with a 3.0 sterile needle. The bowel content was then gently squeezed to allow passage of $1 \mathrm{~mL}$ of liquid content of the bowel into the peritoneal cavity. The peritoneal cavity and the abdominal wall were then closed in layers. Ten rabbits were subject to only opening and closure of the peritoneal cavity and were studied as sham-operated animals.

The remaining animals were randomly assigned into four study groups as follows.

- Group A $(n=12)$ : controls, i.e. infected animals administered $30 \mathrm{~mL}$ of normal saline i.v. $0.5 \mathrm{~h}$ post operatively; the infusion time was $30 \mathrm{~min}$. Animals were also administered $2 \mathrm{~mL}$ bolus infusion of normal saline $2 \mathrm{~h}$ post operatively.

- Group B ( $n=15)$ : infected animals administered $80 \mathrm{mg} / \mathrm{kg}$ clarithromycin $0.5 \mathrm{~h}$ post operatively as described previously [4]; the infusion time was $30 \mathrm{~min}$. Animals were also administered $2 \mathrm{~mL}$ bolus infusion of normal saline $2 \mathrm{~h}$ post operatively. Clarithromycin was provided as pyrogen-free amorphous powder (Abbott, Chicago, IL) and was reconstituted with $10 \mathrm{~mL}$ of $5 \%$ glucose and added to $\mathrm{NaCl} 0.9 \%$ at a final volume of $30 \mathrm{~mL}$.

- Group C $(n=10)$ : infected animals administered $30 \mathrm{~mL}$ of normal saline i.v. 0.5 hours post operatively; the infusion time was $30 \mathrm{~min}$. Animals were also administered piperacillin/tazobactam (TZP) as a $400 \mathrm{mg} / \mathrm{kg} 2 \mathrm{~mL}$ bolus infusion in normal saline $2 \mathrm{~h}$ post operatively. The dose of TZP was selected in accordance with previous studies [12].

- Group D $(n=12)$ : infected animals administered both clarithromycin and TZP in the regimens described above for Groups B and C. 
Single doses of agents were administered in an attempt to discern better the changes in the immune responses over time in each study group.

A volume of $3 \mathrm{~mL}$ of blood was sampled from the vein of the left ear of each animal under aseptic conditions before the operation and at 2, 4, 24 and $48 \mathrm{~h}$. Blood was collected in heparin-coated tubes for flow cytometry and stimulation assays.

Survival of animals was recorded every $12 \mathrm{~h}$ for a total follow-up period of 10 days. Autopsy was performed following death; animals remaining alive after 10 days of follow-up were sacrificed by i.v. administration of sodium thiopental. Under sterile conditions, segments from the right kidney, liver, spleen and lower lobe of the right lung were taken and placed in separate sterile plastic containers for quantitative cultures and biopsy.

\subsection{Cell apoptosis and cell stimulation}

Peripheral blood mononuclear cells (PBMCs) were isolated following gradient centrifugation of heparinised whole blood over Ficoll (Biochrom, Berlin, Germany). Following three consecutive washings in ice-cold phosphate-buffered saline (pH 7.2) (Biochrom), PBMCs were counted in a Neubauer chamber after trypan blue exclusion of dead cells. One-half of the PBMCs were stained with the protein ANNEXIN-V conjugated to the fluorochrome fluorescein isothiocyanate (FITC) (emission $525 \mathrm{~nm}$ ) (Immunotech, Marseille, France) and with propidium iodine (PI) (emission $575 \mathrm{~nm}$ ) (Immunotech). Cells were analysed after running through an EPICS XL/MSL flow cytometer (Beckman Coulter Co., Miami, FL) with separate 
gating for lymphocyte and monocyte cells based on their characteristic forward scattering and side scattering. Cells staining positive for FITC-conjugated ANNEXIN$\mathrm{V}$ and negative for $\mathrm{PI}$ were considered early apoptotic.

The remaining one-half of the PBMCs were distributed into the wells of a 96-well plate at a final volume of $0.2 \mathrm{~mL} /$ well with RMPI 1640 enriched with $10 \%$ fetal bovine serum (FBS) (Biochrom), $2 \mathrm{mM}$ glutamine and $10 \mathrm{mM}$ pyruvate at a density of $2 \times$ $10^{6}$ PBMCs $/ \mathrm{mL}$. Cells were stimulated without or with $10 \mathrm{ng} / \mathrm{mL}$ LPS of Escherichia coli O55:B5, which is a TLR4 ligand (Sigma Chemical Co., St Louis, MO), or without or with $5 \mu \mathrm{g} / \mathrm{mL}$ Pam3Cys-SKKK (EMC Microcollections $\mathrm{GmbH}$, Tübingen, Germany), which a TLR2 ligand. The plates were incubated for $24 \mathrm{~h}$ at $37^{\circ} \mathrm{C}$ in $5 \%$ $\mathrm{CO}_{2}$. Following incubation, plates were centrifuged and the supernatants were collected and stored at $-70^{\circ} \mathrm{C}$ until assayed for TNF $\alpha$. All stimulation assays were performed in duplicate.

\subsection{Bioassay for measurement of $T N F \alpha$}

TNF $\alpha$ was measured by bioassay on an L929 fibrosarcoma cell line as described previously [4-8]. Briefly, confluent cells were thoroughly washed with Hank's solution and were harvested with $0.25 \%$ trypsin $/ 0.02 \%$ ethylenediamine tetra-acetic acid (EDTA) (Biochrom). Cells were centrifuged, re-suspended in RMPI 1640 supplemented with 10\% FBS and $2 \mathrm{mM}$ glutamine, and were distributed into a 96well cell culture plate at a density of $1 \times 10^{5}$ cells/well. The final volume of fluid in each well was $0.05 \mathrm{~mL}$. Following incubation for $2 \mathrm{~h}$ at $37^{\circ} \mathrm{C}$ at $5 \% \mathrm{CO}_{2}, 0.06 \mathrm{~mL}$ of supernatant or standard dilutions of known concentrations of human TNF $\alpha$ (Sigma 
Chemical Co.) (range 5.75-375.00 pg/mL) were added into each well followed by $0.05 \mathrm{~mL}$ of a $0.3 \mathrm{mg} / \mathrm{mL}$ dilution of cycloheximide (Sigma Chemical Co.) to inhibit de novo protein biosynthesis. Following overnight incubation, the supernatant of each well was discarded by aspiration and $0.1 \mathrm{~mL}$ of a $0.5 \mathrm{mg} / \mathrm{mL}$ methylene blue solution in methanol $99 \%$ was added. After 10 min the dye was removed and the wells were thoroughly washed three times with $0.9 \% \mathrm{NaCl}$. Wells were left to dry and remnants of the dye in each well was solublised by addition of $0.1 \mathrm{~mL}$ of $50 \%$ glacial acetic acid (Merck, Darmstadt, Germany). The optical density in each well was read at $495 \mathrm{~nm}$ $\left(\mathrm{OD}_{495}\right)$ using a Hitachi spectrophotometer (Hitachi, Tokyo, Japan) against blank wells and control wells without added serum. Concentrations of TNF $\alpha$ were estimated by reduction in the $\mathrm{OD}_{495}$ of control wells by unknown samples applying a standard curve generated by standard concentrations. All determinations were performed in quadruplicate. The lower limit of detection was $11.5 \mathrm{pg} / \mathrm{mL}$. The interday coefficient of variation of the assay was $13.75 \%$.

\subsection{Tissue cultures}

Tissue segments were weighed and homogenised. One $0.1 \mathrm{~mL}$ aliquot was diluted $1: 10$ in sterile $\mathrm{NaCl}$ four consecutive times. Another aliquot of $0.1 \mathrm{~mL}$ of each dilution was plated onto MacConkey agar and was incubated at $35^{\circ} \mathrm{C}$ for a total period of 3 days. Plates were incubated at $35^{\circ} \mathrm{C}$ and the number of viable colonies was counted in each dilution and was multiplied by the appropriate dilution factor. Identification of bacteria was performed by the API20E and API20NE systems (bioMérieux, Paris, France). The lower limit of detection was 30 colony-forming units/g. Bacterial cells were expressed by their $\log _{10}$ value. 


\subsection{Statistical analysis}

The Kolmogorov-Smirnov test proved that the sample values of early apoptosis of lymphocytes and monocytes at all measured times did not deviate from the normal distribution, allowing for the application of parametric procedures. Specifically in the applied one-way analysis of variance (ANOVA) procedures the main question to be answered was whether the clarithromycin group differed significantly from the other experimental groups and at what times. This issue was addressed with post-hoc Dunnett's tests using the clarithromycin group (Group B) as the control category for comparisons. For each series of measurements, the pharmacokinetic value of the area under the concentration-time curve (AUC) for the first $4 \mathrm{~h}$ was calculated using the trapezoid rule. These AUCs were also compared using the above statistical procedures.

To define whether clarithromycin changed the ability of PBMCs to release TNF $\alpha$ after stimulation with LPS or Pam3Cys, the ratios of released TNF $\alpha$ after stimulation to the same concentrations without stimulation were calculated for every time of sampling. These ratios did not follow the normal distribution, therefore before subjecting them to the same ANOVA procedure as described above the values were log-transformed. For the same reason, the four experimental groups were described through their geometric means and 95\% confidence intervals (Cls).

\section{Results}

None of the sham-operated animals died. Eleven animals died in Group A (controls) (survival 8.3\%), 14 animals died in Group B (treatment with clarithromycin) (survival 
6.7\%), 9 died animals in group C (treatment with TZP) (survival 10.0\%) and 5 animals died in group D (treatment with both agents) (survival 58.3\%) $(P<0.0001$ by Pearson's $\chi^{2}$ test) (Fig. 1). Survival in Group D was prolonged compared with Group A (log-rank, 3.95; $P=0.047$ ). Survival in Groups $B$ and $C$ was not prolonged compared with Group A.

The study of the influence of treatment with clarithromycin on the immune response of the host involved a study on (a) the effect of cell apoptosis and (b) the innate immune response. Mean \pm standard error (S.E.) early apoptosis of lymphocytes in sham-operated animals at 2, 4, 24 and $48 \mathrm{~h}$ was $42.89 \pm 6.58 \%, 45.81 \pm 3.60 \%$, $34.92 \pm 4.03 \%$ and $37.94 \pm 9.19 \%$, respectively. The comparative rate of early apoptosis of lymphocytes during follow-up is shown in Fig. 2. As shown in Fig. 2, the rate of early apoptosis of lymphocytes in the clarithromycin group (B) was lower over almost the whole range of time measurements. Thus, overall apoptosis expressed through the areas under the corresponding curves are significantly lower. The corresponding mean \pm S.D. values of the 4-h AUCs for the four groups were: Group A, $74.5 \pm 31.7$; Group B, $48.3 \pm 34.5$; Group C, $77.8 \pm 12.3$; and Group D, $81.3 \pm$ 32.8. It is interesting to note that the mean values of the three experimental Groups $A, C$ and $D$ are very close together but, as the Dunnett's post-hoc test showed, were significantly greater than for the clarithromycin group (B). In addition, the Dunnett's post-hoc test showed statistically significant differences of the clarithromycin treatment group (B) in comparison with Group D at $2 \mathrm{~h}$ and in comparison with Group $\mathrm{C}$ at $4 \mathrm{~h}$ post operatively. 
Mean \pm S.E. early apoptosis of monocytes of sham-operated animals at 2, 4, 24 and $48 \mathrm{~h}$ was $59.59 \pm 7.03 \%, 61.69 \pm 4.14 \%, 60.28 \pm 5.93 \%$ and $62.45 \pm 2.42 \%$, respectively. The comparative rate of early apoptosis of monocytes during follow-up is shown in Fig. 3. The same pattern as with lymphocytes is observed for monocytes, only in this case although the values for the clarithromycin group (B) are lower than for the three other groups, the differences do not achieve statistical significance except in the case of the Dunnett's post-hoc comparison with Group C (TZP) at $24 \mathrm{~h}$.

PBMCs isolated at baseline and post operatively were assayed for ex vivo production of TNF $\alpha$ as an index of the innate immune function of rabbits. The geometric means and their $95 \% \mathrm{Cls}$ of the ratios of the concentrations of TNF $\alpha$ after stimulation with LPS to the same concentrations without stimulation at the 2-h measurement for the four experimental groups are shown in Fig. 4. As the Dunnett's post-hoc test has shown for the 2-h measurements, the clarithromycin group (B) had the lowest values, which are significantly lower than the control group $(A)$ and the combination group (D). No differences were found between Group B and the other groups at any other time of sampling (data not shown).

Comparison of the geometric means and their $95 \% \mathrm{Cls}$ of the ratios of the concentrations of TNF $\alpha$ after stimulation with Pam3Cys to the same concentrations without stimulation for the four experimental groups failed to disclose any differences at any time of sampling (data not shown).

Bacterial species isolated from tissues were E. coli, Enterobacter cloacae and Enterococcus spp. Their counts are shown in Fig. 5. Bacterial growth in tissues of 
animals in Groups $C$ and D was significantly lower than growth in tissues of Group A. Those of Group B did not differ from Group A.

\section{Discussion}

The pathogenesis of sepsis is considered to follow two phases. In the first phase, hyperactivation of the innate immune system takes place. Notably, a burst of proinflammatory cytokines is produced when PAMPs of the invading pathogens bind to PRRs of cells of the innate immune system. Produced cytokines effect the systemic inflammatory response. In the second phase, hypoactivation of the innate immune system predominates. In this latter stage, blood monocytes are not able to produce an adequate amount of cytokines once activated by PAMPs. Moreover, apoptosis of lymphocytes supervenes. This second stage is also described as a stage of immunoparalysis of the septic host when organ failure and MODS arrive. This distinction of phases is most important for the type of administered immunointervention, since some agents such as those targeting TNF $\alpha$ act as an antiinflammatory, and others such as interferon-gamma (IFN $\gamma$ ) are pro-inflammatory; however, it is very difficult to discern at which phase each patient lies [2].

Recent data from the Hellenic Sepsis Study Group showed that both the innate and adaptive immune responses differ according to the underlying type of infection, particularly the kinetics of how a systemic inflammatory response transits into severe sepsis and/or septic shock. This appears to be of particular relevance for IAls. More precisely, the rate of apoptosis of lymphocytes and the rate of anergy of monocytes in sepsis developing from IAI are greater compared with sepsis developing from other types of infections [13]. As a consequence, when immunointervention is 
considered for abdominal sepsis, these unique characteristics of pathogenesis should be taken into consideration.

Clarithromycin has been shown to be a successful immunomodulator in sepsis. When co-administered with antibiotics, survival was prolonged in an animal model of acute pyelonephritis [4-8]. In the clinical setting, clarithromycin decreased relative risk of death from septic shock and MODS among patients with VAP [9].

In the present study, clarithromycin was administered in an animal model of polymicrobial sepsis. This model is similar to everyday clinical practice owing to its great lethality as well as the dissemination of a variety of Gram-positive and Gramnegative pathogens to deep organs. Clarithromycin or TZP also could not alter the physical course. However, when clarithromycin and TZP were co-administered, survival was prolonged. This study focused on the effect of clarithromycin in the function of the innate and adaptive immune responses. These are intensively followed-up over consecutive time intervals, an approach never previously described for experimental models of sepsis.

The reported findings suggest that clarithromycin may act in at least two different sites: modulation of the immune response and enhanced clearance of pathogens. Modulation of the immune response by clarithromycin is shown both in the rate of apoptosis of lymphocytes and monocytes and in the innate immune responses. The latter are measured through ex vivo stimulation of TNF $\alpha$ production by PBMCs. Early apoptosis of lymphocytes and monocytes increase within the first $2 \mathrm{~h}$ post induction of peritonitis in infected controls. Following treatment with clarithromycin, release of 
TNF $\alpha$ after ex vivo stimulation with a TLR4 agonist from blood monocytes decreased. We assume that this observed effect of clarithromycin may be of importance for the management of the septic host. Induction of apoptosis of lymphocytes and inadequate release of cytokines from monocytes are characteristics of the second hypoinflammatory phase of sepsis [2]. The results show that clarithromycin may well interfere with this phase.

It should be underscored that the effects of clarithromycin in the immune system were predominantly shown when it was given alone and not in combination with TZP. A clear explanation for this finding does not exist. One probable explanation lies in a pharmacokinetic interaction between the agents.

Apart from the assumed effect of clarithromycin in the stage of immunoparalysis, part of its effect may be mediated through enhancement of clearance of pathogens, since a trend was observed for tissue bacterial growth of clarithromycin-treated rabbits to be lower compared with non-treated animals. Isolated bacteria from tissues, namely members of the Enterobacteriaceae and enterococci, are not part of the antimicrobial spectrum of macrolides. Although the present study does not provide any data on blood neutrophils, it has been reported that macrolides may enhance phagocytosis of bacteria by neutrophils [14]. The studied effect of clarithromycin on the function of blood monocytes may also favour improved clearance of offending pathogens.

Two main limitations of this study should be addressed. First, single doses of clarithromycin and TZP were administered. However, this allowed the immunomodulatory effect of clarithromycin to be disclosed clearly within the first $2 \mathrm{~h}$ 
post administration. Such an effect could not be demonstrated later when clarithromycin levels were expected to decrease in the systemic circulation. Second, tissue cultures were performed on MacConkey agar. This growth medium mainly favours isolation of Enterobacteriaceae, enterococci and certain species of staphylococci. As a consequence, the effect of treatment on other pathogens such as anaerobes cannot be estimated.

The results presented here show that clarithromycin administered in an animal model of peritonitis modulates the function of the immune response of the host. This was mediated through a decreased rate of early apoptosis of lymphocytes and monocytes and by decreased ex vivo release of TNF $\alpha$ by blood monocytes. These experimental results, in light of the beneficial results of i.v. administration in patients with VAP [9], create a novel perspective for a role of clarithromycin in the management of the septic host.

\section{Funding}

None.

\section{Competing interests}

EJG-B has received independent educational grants from Abbott Hellas SA, Wyeth Hellas SA and Sanofi-Aventis (Greece) and from BRAHMS GmbH (Germany).

\section{Ethical approval}


This study received a permit from the Veterinary Directorate of the Prefecture of Thessaloniki according to Greek legislation in conformance with the 160/1991 Council Directive of the European Union. 


\section{References}

[1] Dellinger RP, Levy MM, Carlet JM, Bion J, Parker MM, Jaeschke R, et al. Surviving Sepsis Campaign: international guidelines for management of severe sepsis and septic shock: 2008. Crit Care Med 2008;36:296-327.

[2] Rittisch D, Flierl MA, Ward PA. Harmful molecular mechanisms in sepsis. Nature Immunol 2008;8:776-86.

[3] Vincent JL, Sun Q, Dubois MJ. Clinical trials of immunomodulatory therapies in severe sepsis and septic shock. Clin Infect Dis 2003;34:1084-93.

[4] Giamarellos-Bourboulis EJ, Adamis T, Laoutaris G, Sabracos L, Koussoulas V, Mouktaroudi M, et al. Immunomodulatory clarithromycin treatment of experimental sepsis and acute pyelonephritis caused by multidrug-resistant Pseudomonas aeruginosa. Antimicrob Agents Chemother 2004;48:93-9.

[5] Giamarellos-Bourboulis EJ, Baziaka F, Antonopoulou A, Koutoukas P, Kousoulas V, Sabracos L, et al. Clarithromycin co-administered with amikacin attenuates systemic inflammation in experimental sepsis by Escherichia coli. Int J Antimicrob Agents 2005;25:168-72.

[6] Giamarellos-Bourboulis EJ, Adamis T, Sabracos L, Raftogiannis M, Baziaka T, Tsaganos T, et al. Clarithromycin: immunomodulatory therapy of experimental sepsis and acute pyelonephritis by Escherichia coli. Scand J Infect Dis $2005 ; 37: 48-54$.

[7] Giamarellos-Bourboulis EJ, Antonopoulou A, Raftogiannis M, Koutoukas P, Tsaganos T, Tziortzioti $\mathrm{V}$, et al. Clarithromycin is an effective immunomodulator when administered late in experimental pyelonephritis by multidrug-resistant Pseudomonas aeruginosa. BMC Infect Dis 2006;6:31. 
[8] Giamarellos-Bourboulis EJ, Tziortzioti V, Koutoukas P, Baziaka F, Antonopoulou A, Adamis $\mathrm{T}$, et al. Clarithromycin is an effective immunomodulator in experimental pyelonephritis caused by pan-resistant Klebsiella pneumoniae. J Antimicrob Chemother 2006;57:937-44.

[9] Giamarellos-Bourboulis EJ, Pechère JC, Routsi C, Plachouras D, Kollias S, Raftogiannis M, et al. Effect of clarithromycin in patients with sepsis and ventilator-associated pneumonia. Clin Infect Dis 2008;46:1157-64.

[10] Hodgin KE, Moss M. The epidemiology of sepsis. Curr Pharm Des 2008;14:1833-9.

[11] Wang $\mathrm{H}, \mathrm{Ma} \mathrm{S}$. The cytokine storm and factors determining the sequence and severity of organ dysfunction in multiple organ dysfunction syndrome. Am J Emerg Med 2008;26:711-5.

[12] Li C, Nikolau DP, Lister PD, Quintiliani R, Nightngale CH. Pharmacodynamic study of $\beta$-lactams alone and in combination with $\beta$-lactamase inhibitors against Pseudomonas aeruginosa possessing an inducible $\beta$-lactamase. J Antimicrob Chemother 2004;53:297-304.

[13] Gogos C, Kotsaki A, Pelekanou A, Giannikopoulos G, Vaki I, Maravitsa P, et al. Early alterations of the innate and adaptive immune statuses in sepsis according to the type of underlying infection. Crit Care 2010;14:R96.

[14] Schultz MJ. Macrolide activities beyond their antimicrobial effects: macrolides in diffuse panbronchiolitis and cystic fibrosis. J Antimicrob Chemother $2004 ; 54: 21-8$. 
Fig. 1. Comparative survival of rabbits subject to experimental peritonitis: Group A, controls ( $n=12)$; Group B, clarithromycin treatment $(n=15)$; Group C, piperacillin/tazobactam (TZP) treatment $(n=10)$; Group D, combination treatment with clarithromycin and TZP $(n=12)$. None of the sham-operated animals died.

Fig. 2. Comparative early apoptosis of lymphocytes during consecutive follow-up of rabbits subject to experimental peritonitis. Error bars are the standard errors of the means. * Denotes statistically significant difference at a $P$-value of 0.05 of the experimental group compared with the clarithromycin group (B) by post-hoc Dunnett's test.

Fig. 3. Comparative early apoptosis of monocytes during consecutive follow-up of rabbits subject to experimental peritonitis. Error bars are the standard errors of the means. * Denotes statistically significant difference at a $P$-value of 0.05 of the experimental group compared with the clarithromycin group (B) by post-hoc Dunnett's test.

Fig. 4. Comparative ratio of 2-h concentrations of tumour necrosis factor-alpha (TNF $\alpha$ ) in supernatants of peripheral blood mononuclear cells of rabbits subject to experimental peritonitis following stimulation with $10 \mathrm{ng} / \mathrm{mL}$ lipopolysaccharide (LPS) to the same concentration without stimulation. Error bars are the $95 \%$ confidence interval of the geometric means. ${ }^{*}$ Denotes statistically significant difference at a $P$ value of 0.05 of the experimental group compared with the clarithromycin group (B) by post-hoc Dunnett's test. 
Fig. 5. Tissue bacterial growth in liver, spleen, right kidney and lower right lung lobe of rabbits subject to experimental peritonitis after death or sacrifice: Group A, controls ( $n=12)$; Group B, clarithromycin treatment $(n=15)$; group C, piperacillin/tazobactam (TZP) treatment $(n=10)$; and Group D, combination treatment with clarithromycin and TZP $(n=12)$. * Denotes statistically significant difference compared with the respective tissue growth of Group A. No bacterial growth was found in tissues of sham-operated animals. CFU, colony-forming units. 


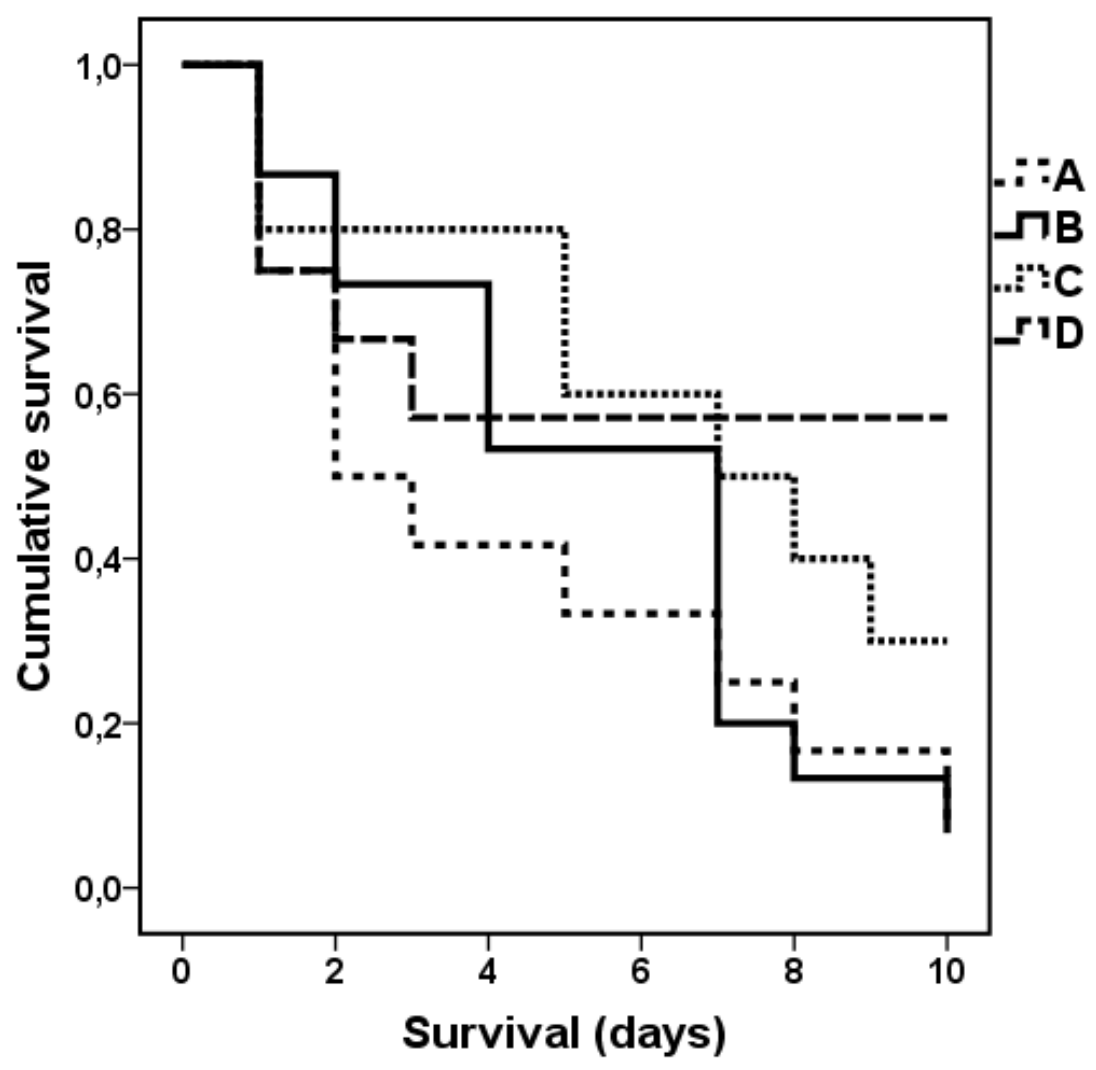




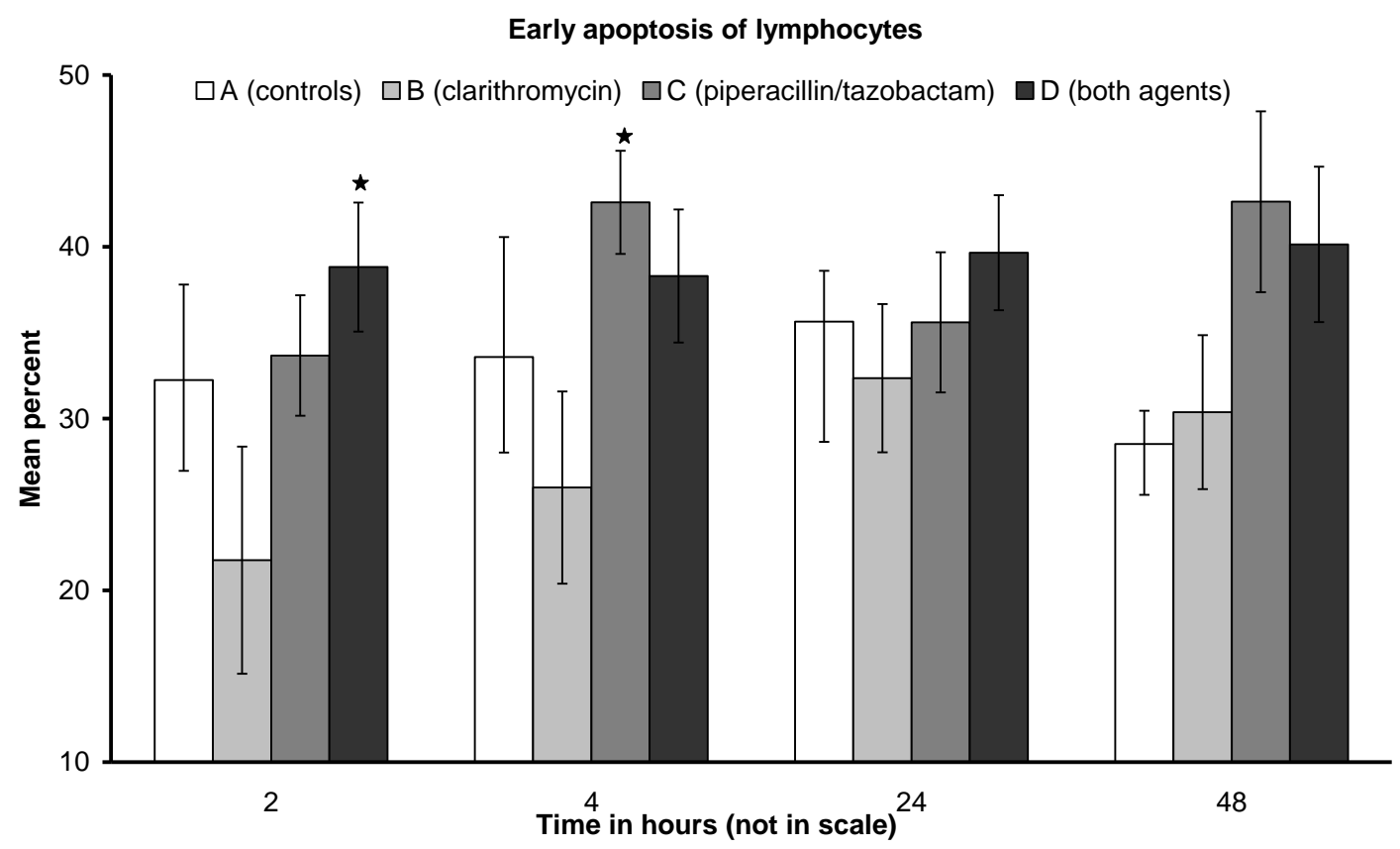




\section{Early apoptosis of monocytes}

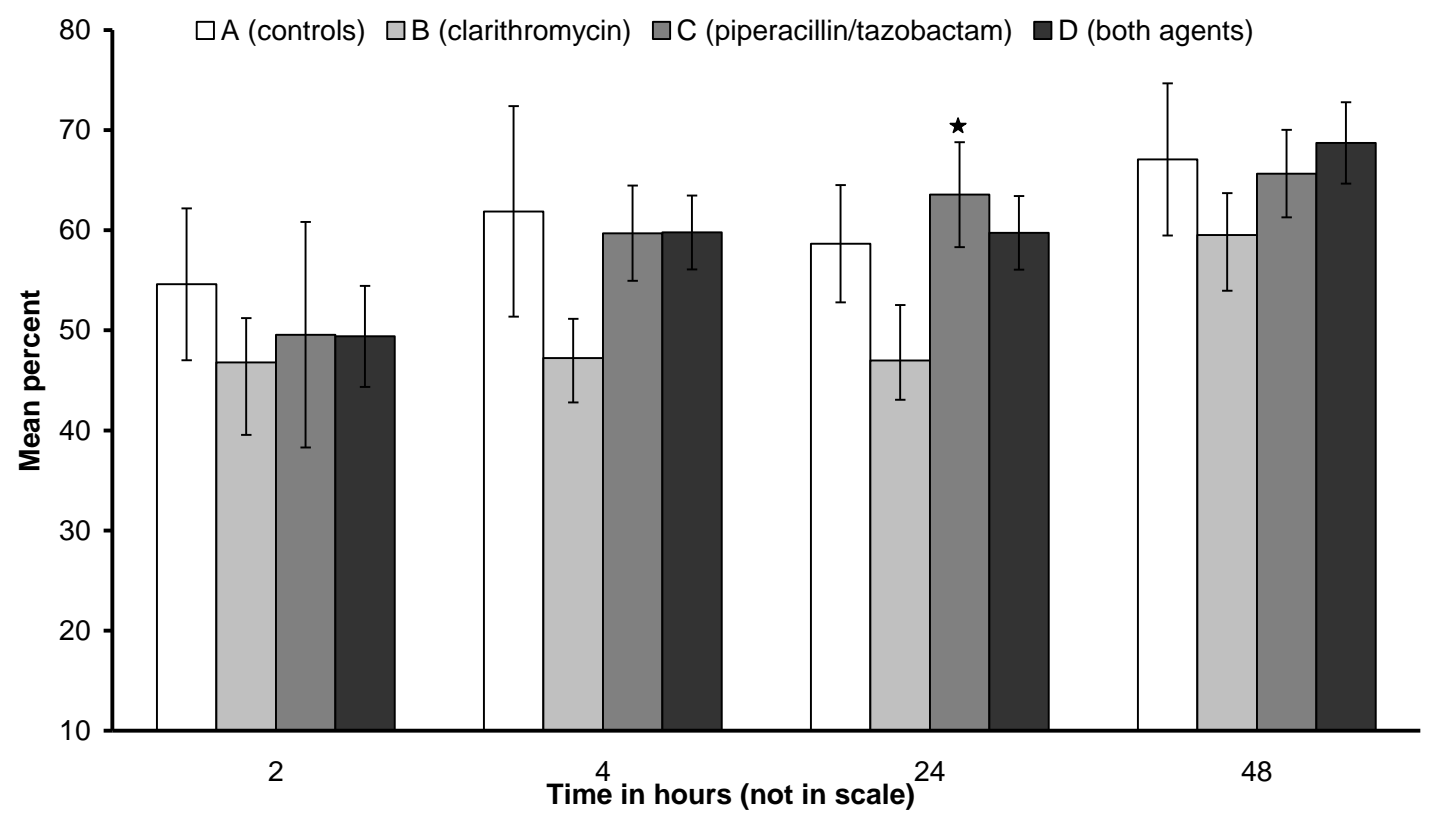




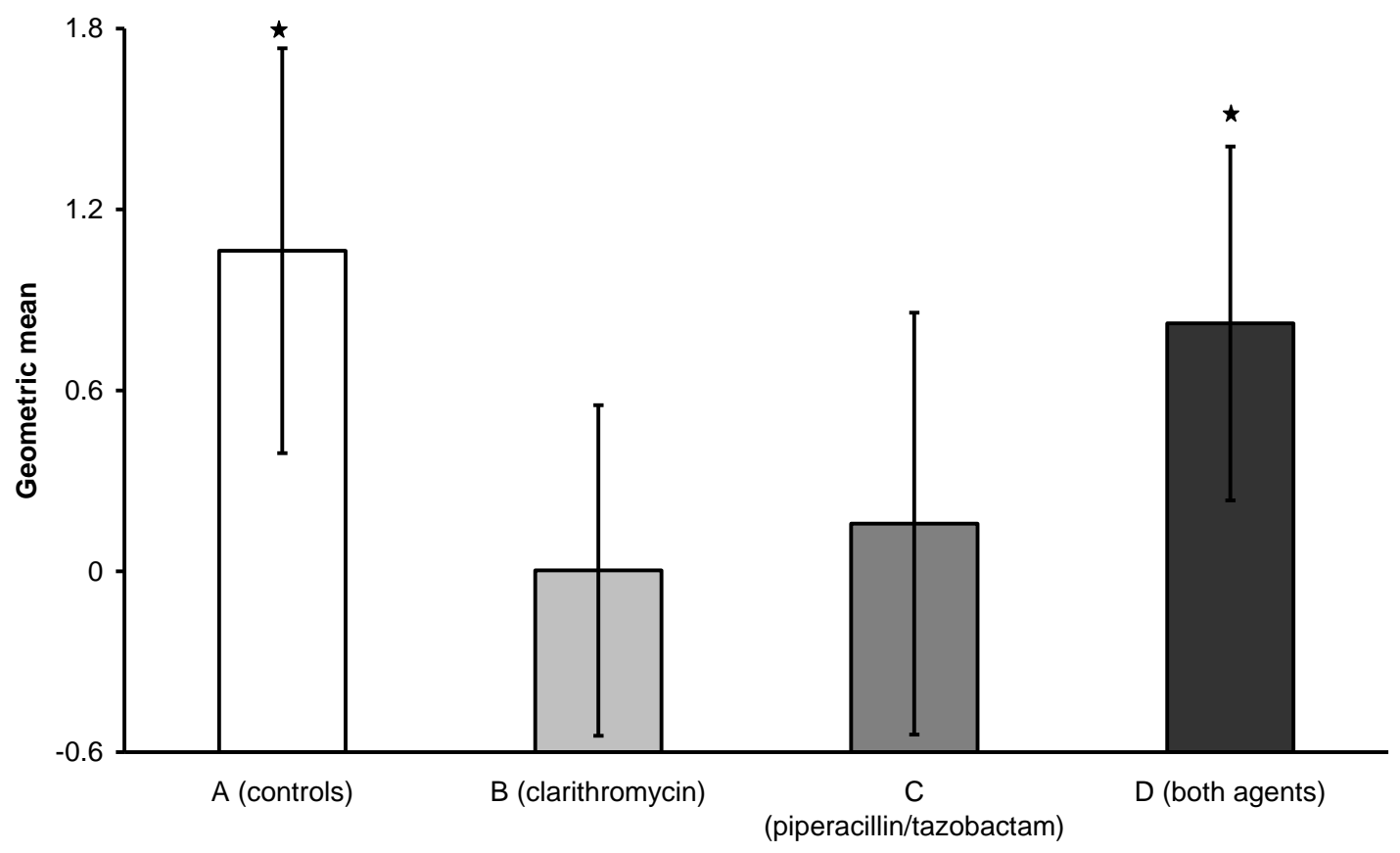


